\title{
Fixed point theorems for fuzzy mappings and applications to ordinary fuzzy differential equations
}

\author{
Hemant Kumar Nashine' ${ }^{1}$, Calogero Vetro ${ }^{2}$, Wiyada Kumam³ ${ }^{*}$ and Poom Kumam ${ }^{4}$
}

\section{"Correspondence:}

wiyada.kum@mail.rmutt.ac.th

${ }^{3}$ Department of Mathematics and

Computer Science, Faculty of

Science and Technology,

Rajamangala University of

Technology Thanyaburi (RMUTT),

39, Moo 1, Rangsit-Nakhonnayok

Rd., Klong 6, Thanyaburi,

Pathumthani, 12110, Thailand

Full list of author information is

available at the end of the article

\begin{abstract}
Ran and Reurings (Proc. Am. Math. Soc. 132(5):1435-1443, 2004) proved an analog of the Banach contraction principle in metric spaces endowed with a partial order and discussed some applications to matrix equations. The main novelty in the paper of Ran and Reurings involved combining the ideas in the contraction principle with those in the monotone iterative technique. Motivated by this, we present some common fixed point results for a pair of fuzzy mappings satisfying an almost generalized contractive condition in partially ordered complete metric spaces. Also we give some examples and an application to illustrate our results.
\end{abstract}

MSC: 46S40; 47H10; 34A70; 54E50

Keywords: altering distance function; complete metric space; fuzzy mapping; ordinary fuzzy differential equation

\section{Introduction}

The Banach contraction principle [1] is a very popular tool in solving existence problems in many branches of mathematical analysis. This famous theorem can be stated as follows.

Theorem 1.1 ([1]) Let $(X, d)$ be a complete metric space and $T$ be a mapping of $X$ into itself satisfying

$$
d(T x, T y) \leq k d(x, y) \quad \text { for all } x, y \in X,
$$

where $k$ is a constant in $(0,1)$. Then $T$ has a unique fixed point $x^{*} \in X$.

There is a great number of generalizations of the Banach contraction principle. In fact, existence theorems of fixed points have been established for mappings defined on various types of spaces and satisfying different types of contractive inequalities. Tasković [2] presented a comprehensive survey of such results in metric spaces. A new category of contractive fixed point problems was addressed by Khan et al. [3] that introduced the concept of altering distance function, which is a control function that alters distance between two points in a metric space (see also [4-6] and references therein).

Definition $1.2([3]) \varphi:[0,+\infty) \rightarrow[0,+\infty)$ is called an altering distance function if the following properties are satisfied:

(อ2014 Nashine et al.: licensee Springer. This is an Open Access article distributed under the terms of the Creative Commons Attribution License (http://creativecommons.org/licenses/by/2.0), which permits unrestricted use, distribution, and reproduction in any medium, provided the original work is properly cited. 
(i) $\varphi$ is continuous and nondecreasing,

(ii) $\varphi(t)=0 \Leftrightarrow t=0$.

Another generalization of the Banach contraction principle was suggested by Alber and Guerre-Delabriere [7] in Hilbert spaces by introducing the concept of weakly contractive mappings as follows.

Definition 1.3 Let $(X, d)$ be a metric space. A mapping $T: X \rightarrow X$ is called weakly contractive if and only if:

$$
d(T x, T y) \leq d(x, y)-\varphi(d(x, y)) \quad \text { for all } x, y \in X
$$

where $\varphi$ is an altering distance function.

Rhoades [6] showed that most results of [7] are still valid for any Banach space. Weak inequalities of the above type have been used to establish fixed point results in a number of subsequent works (see $[4,5,8-10]$ and references therein).

Recently, many results appeared related to fixed points in complete metric spaces endowed with a partial ordering $\preceq$. Most of them are hybrids of two fundamental principles: the Banach contraction principle and the monotone iterative technique. In fact, these results deal with a monotone (either order-preserving or order-reversing) self-mapping $T$ satisfying, with some restrictions, a classical contractive condition and such that for some $x_{0} \in X$, either $x_{0} \preceq T x_{0}$ or $T x_{0} \preceq x_{0}$. The first result in this direction was given by Ran and Reurings [11, Theorem 2.1]. In their paper, Ran and Reurings proved an analog of the Banach contraction principle in a metric space endowed with a partial ordering and gave applications to matrix equations. Subsequently, Nieto and Rodríguez-López [12] extended the result of Ran and Reurings [11] for nondecreasing mappings and applied to obtain a unique solution for a first order ordinary differential equation with periodic boundary conditions. Thereafter, many works related to fixed point problems have also been considered in partially ordered probabilistic metric spaces [13], partially ordered G-metric spaces $[14,15]$, partially ordered cone metric spaces [16], partially ordered fuzzy metric spaces [17-22] and partially ordered non-Archimedean fuzzy metric spaces [23, 24]. For other related works one is referred to [11, 22, 25-31].

On the other hand, in the year 1965, Zadeh [32] introduced the concept of fuzzy set which motivated a lot of mathematical activities on generalization of the notion of fuzzy set. Heilpern [33] introduced the concept of fuzzy mapping and proved a fixed point theorem for fuzzy contraction mappings, which was successively generalized by Estruch and Vidal [34]. Afterward, a number of papers appeared in which fixed points of fuzzy mappings satisfying contractive inequalities have been discussed (see [35-37] and references therein). Recently, many authors studied fixed point results for application to partial differential equation and integral equations (see [38-43]).

Now, we briefly describe our reasons for being interested in results of this kind. The applications of fixed point theorems are remarkable in different disciplines of mathematics, engineering and economics in dealing with problems arising in approximation theory, game theory and many others (see [44] and references therein). 
Motivated by this, we prove a common fixed point theorem for a pair of fuzzy mappings without taking into account any commutativity condition in complete ordered metric spaces. The key feature of our theorem is that the contractive condition is only assumed to hold on elements that are comparable in respect to the partial ordering. We show that under such conditions, the conclusions of previous fixed point theorems of fuzzy mappings still hold. The main result is based on an almost generalized contractive condition and generalizes, improves and extends many known results in the comparable literature $[4-6,17,35]$ in the sense of fuzziness under ordered metric spaces. At the end of the paper, we remark that some of the ideas existing in the literature can also be used to extend our result.

\section{Preliminaries}

For the sake of completeness, we briefly recall some basic concepts used in the sequel.

Throughout the rest of the paper unless otherwise stated $(X, d)$ stands for a complete metric space. A fuzzy set in $X$ is a function with domain $X$ and values in $[0,1]$. If $A$ is a fuzzy set on $X$ and $x \in X$, then the functional value $A x$ is called the grade of membership of $x$ in $A$. The $\alpha$-level set of $A$, denoted by $A_{\alpha}$, is defined by

$$
A_{\alpha}=\{x: A x \geq \alpha\} \quad \text { if } \alpha \in(0,1], \quad A_{0}=\overline{\{x: A x>0\}},
$$

where $\bar{A}$ denotes the closure of the set $A$. For any two subsets $A$ and $B$ of $X$ we denote by $H(A, B)$ the Hausdorff distance.

Definition 2.1 A fuzzy set $A$ in a metric linear space is said to be an approximate quantity iff $A_{\alpha}$ is compact and convex in $X$ for each $\alpha \in[0,1]$ and $\sup _{x \in X} A x=1$.

Let $I=[0,1]$ and $W(X) \subset I^{X}$ be the collection of all approximate quantities in $X$. For $\alpha \in[0,1]$, the family $W_{\alpha}(X)$ is given by $\left\{A \in I^{X}: A_{\alpha}\right.$ is nonempty and compact $\}$.

For a metric space $(X, d)$ we denote by $V(X)$ the collection of fuzzy sets $A$ in $X$ for which $A_{\alpha}$ is compact and $\sup A x=1$ for all $\alpha \in[0,1]$. Clearly, when $X$ is a metric linear space, $W(X) \subset V(X)$.

Definition 2.2 Let $A, B \in V(X), \alpha \in[0,1]$. Then

$$
p_{\alpha}(A, B)=\inf _{x \in A_{\alpha}, y \in B_{\alpha}} d(x, y), \quad D_{\alpha}(A, B)=H\left(A_{\alpha}, B_{\alpha}\right),
$$

where $H$ is the Hausdorff distance.

Definition 2.3 Let $A, B \in V(X)$. Then $A$ is said to be more accurate than $B$ (or $B$ includes $A$ ), denoted by $A \subset B$, if and only if $A x \leq B x$ for each $x \in X$.

According to [45], for $x \in X$ we write $\{x\}$ the characteristic function of the ordinary subset $\{x\}$ of $X$. For $\alpha \in(0,1]$ the fuzzy point $x_{\alpha}$ of $X$ is the fuzzy set of $X$ given by $x_{\alpha}(x)=\alpha$ and $x_{\alpha}(z)=0$ if $z \neq x$. Then we give the following definition.

Definition 2.4 Let $x_{\alpha}$ be a fuzzy point of $X$. We will say that $x_{\alpha}$ is a fixed fuzzy point of the fuzzy mapping $F$ over $X$ if $x_{\alpha} \subset F x$ (i.e., the fixed degree of $x$ for $F$, say $(F x)(x)$, is at 
least $\alpha$ ) [34]. In particular, and according to [33], if $\{x\} \subset F x$, we say that $x$ is a fixed point of $F$.

To complete the proof of our main result, we need the following lemma.

Lemma 2.5 ([33]) Let $(X, d)$ be a metric space, $x, y \in X$ and $A, B \in W(X)$ :

(1) if $p_{\alpha}(x, A)=0$, then $x_{\alpha} \subset A$,

(2) $p_{\alpha}(x, A) \leq d(x, y)+p_{\alpha}(y, A)$,

(3) if $x_{\alpha} \subset A$, then $p_{\alpha}(x, B) \leq D_{\alpha}(A, B)$.

Definition 2.6 Let $X$ be a nonempty set. Then $(X, d, \preceq)$ is called an ordered metric space if and only if:

(i) $(X, d)$ is a metric space,

(ii) $(X, \preceq)$ is partially ordered.

Definition 2.7 Let $(X, \preceq)$ be a partially ordered set. Then $x, y \in X$ are called comparable if $x \preceq y$ or $y \preceq x$ holds.

\section{Main results}

Denote with $\Phi$, the family of nondecreasing functions $\varphi:[0,+\infty) \rightarrow[0,+\infty)$ such that $\sum_{n=1}^{\infty} \varphi^{n}(t)<\infty$ for all $t>0$. The next lemma is obvious.

Lemma 3.1 If $\varphi \in \Phi$, then $\varphi(0)=0$ and $\varphi(t)<t$ for each $t>0$.

Our first result is the following common fixed point theorem involving an almost generalized contractive condition.

Theorem 3.2 Let $(X, d, \preceq)$ be a complete ordered metric space and $T_{1}, T_{2}: X \rightarrow W_{\alpha}(X)$ be two fuzzy mappings satisfying

$$
D_{\alpha}\left(T_{1} x, T_{2} y\right) \leq \varphi(M(x, y))+\mathbf{L} \min \left\{p_{\alpha}\left(x, T_{1} x\right), p_{\alpha}\left(y, T_{2} y\right), p_{\alpha}\left(x, T_{2} y\right), p_{\alpha}\left(y, T_{1} x\right)\right\}
$$

for all comparable elements $x, y \in X$, where $\mathbf{L} \geq 0$ and

$$
M(x, y)=\max \left\{d(x, y), p_{\alpha}\left(x, T_{1} x\right), p_{\alpha}\left(y, T_{2} y\right), \frac{1}{2}\left[p_{\alpha}\left(x, T_{2} y\right)+p_{\alpha}\left(y, T_{1} x\right)\right]\right\} .
$$

Also suppose that

(i) if $y \in\left(T_{1} x_{0}\right)_{\alpha}$, then $y, x_{0} \in X$ are comparable,

(ii) if $x, y \in X$ are comparable, then every $u \in\left(T_{1} x\right)_{\alpha}$ and every $v \in\left(T_{2} y\right)_{\alpha}$ are comparable,

(iii) if a sequence $\left\{x_{n}\right\}$ in $X$ converges to $x \in X$ and its consecutive terms are comparable, then $x_{n}$ and $x$ are comparable for all $n$.

Then there exists a point $x \in X$ such that $x_{\alpha} \subset T_{1} x$ and $x_{\alpha} \subset T_{2} x$.

Proof Let $x_{0}$ in $X$. Since $\left(T_{1} x_{0}\right)_{\alpha} \neq \emptyset$, then there exists $x_{1} \in X$ such that $x_{1} \in\left(T_{1} x_{0}\right)_{\alpha}$. By assumption (i), $x_{0}$ and $x_{1}$ are comparable. Since $\left(T_{2} x_{1}\right)_{\alpha}$ is a nonempty compact subset of 
$X$, there exists $x_{2} \in\left(T_{2} x_{1}\right)_{\alpha}$ such that

$$
d\left(x_{1}, x_{2}\right)=p_{\alpha}\left(x_{1}, T_{2} x_{1}\right) \leq D_{\alpha}\left(T_{1} x_{0}, T_{2} x_{1}\right) .
$$

Moreover, $x_{1}$ and $x_{2}$ are comparable. Continuing this process, one obtains a sequence $\left\{x_{n}\right\}$ in $X$ such that $x_{2 n+1} \in\left(T_{1} x_{2 n}\right)_{\alpha}$ and $x_{2 n+2} \in\left(T_{2} x_{2 n+1}\right)_{\alpha}$ for all $n \geq 0, x_{2 n}$ and $x_{2 n+1}$ are comparable and

$$
d\left(x_{2 n+1}, x_{2 n+2}\right) \leq D_{\alpha}\left(T_{1} x_{2 n}, T_{2} x_{2 n+1}\right) .
$$

Since $x_{2 n}$ and $x_{2 n+1}$ are comparable, by taking $x_{2 n}$ for $x$ and $x_{2 n+1}$ for $y$ in the inequality (1), it follows that

$$
\begin{aligned}
d\left(x_{2 n+1}, x_{2 n+2}\right) \leq & D_{\alpha}\left(T_{1} x_{2 n}, T_{2} x_{2 n+1}\right) \\
\leq & \varphi\left(M\left(x_{2 n}, x_{2 n+1}\right)\right)+\mathbf{L} \min \left\{p_{\alpha}\left(x_{2 n}, T_{1} x_{2 n}\right),\right. \\
& \left.p_{\alpha}\left(x_{2 n+1}, T_{2} x_{2 n+1}\right), p_{\alpha}\left(x_{2 n}, T_{2} x_{2 n+1}\right), p_{\alpha}\left(x_{2 n+1}, T_{1} x_{2 n}\right)\right\},
\end{aligned}
$$

where

$$
\begin{aligned}
M\left(x_{2 n}, x_{2 n+1}\right)= & \max \left\{d\left(x_{2 n}, x_{2 n+1}\right), p_{\alpha}\left(x_{2 n}, T_{1} x_{2 n}\right), p_{\alpha}\left(x_{2 n+1}, T_{2} x_{2 n+1}\right),\right. \\
& \left.\frac{1}{2}\left[p_{\alpha}\left(x_{2 n}, T_{2} x_{2 n+1}\right)+p_{\alpha}\left(x_{2 n+1}, T_{1} x_{2 n}\right)\right]\right\} \\
= & \max \left\{d\left(x_{2 n}, x_{2 n+1}\right), p_{\alpha}\left(x_{2 n}, T_{1} x_{2 n}\right), p_{\alpha}\left(x_{2 n+1}, T_{2} x_{2 n+1}\right),\right. \\
& \left.\frac{1}{2} p_{\alpha}\left(x_{2 n}, T_{2} x_{2 n+1}\right)\right\} \\
\leq & \max \left\{d\left(x_{2 n}, x_{2 n+1}\right), d\left(x_{2 n+1}, x_{2 n+2}\right), \frac{1}{2} d\left(x_{2 n}, x_{2 n+2}\right)\right\} \\
= & \max \left\{d\left(x_{2 n}, x_{2 n+1}\right), d\left(x_{2 n+1}, x_{2 n+2}\right)\right\} .
\end{aligned}
$$

Therefore from (2), we have

$$
d\left(x_{2 n+1}, x_{2 n+2}\right) \leq \varphi\left(\max \left\{d\left(x_{2 n}, x_{2 n+1}\right), d\left(x_{2 n+1}, x_{2 n+2}\right)\right\}\right) .
$$

If $d\left(x_{2 n}, x_{2 n+1}\right)=0$, it follows that $d\left(x_{2 n+1}, x_{2 n+2}\right)=0$. Now, $x_{2 n}=x_{2 n+1}=x_{2 n+2}$ implies $x_{2 n+1} \in$ $\left(T_{1} x_{2 n}\right)_{\alpha}=\left(T_{1} x_{2 n+1}\right)_{\alpha}$ and $x_{2 n+1}=x_{2 n+2} \in\left(T_{2} x_{2 n+1}\right)_{\alpha}$, then the proof is finished. Therefore, we assume $d\left(x_{2 n}, x_{2 n+1}\right)>0$. By Lemma 3.1, we get $\varphi(t)<t$ for each $t>0$.

Consequently, if $d\left(x_{2 n+1}, x_{2 n+2}\right)>d\left(x_{2 n}, x_{2 n+1}\right)$, for some $n$, then we have

$$
d\left(x_{2 n+1}, x_{2 n+2}\right) \leq \varphi\left(d\left(x_{2 n+1}, x_{2 n+2}\right)\right)<d\left(x_{2 n+1}, x_{2 n+2}\right),
$$

which is a contradiction. Therefore

$$
d\left(x_{2 n+1}, x_{2 n+2}\right) \leq \varphi\left(d\left(x_{2 n}, x_{2 n+1}\right)\right)<d\left(x_{2 n}, x_{2 n+1}\right),
$$


that is,

$$
d\left(x_{2 n+1}, x_{2 n+2}\right)<d\left(x_{2 n}, x_{2 n+1}\right) .
$$

Similarly it can be shown that

$$
d\left(x_{2 n+3}, x_{2 n+2}\right) \leq \varphi\left(d\left(x_{2 n+2}, x_{2 n+1}\right)\right)<d\left(x_{2 n+2}, x_{2 n+1}\right),
$$

that is,

$$
d\left(x_{2 n+3}, x_{2 n+2}\right)<d\left(x_{2 n+2}, x_{2 n+1}\right) .
$$

Therefore, for all $n$, we get

$$
\begin{aligned}
d\left(x_{n}, x_{n+1}\right) \leq & \varphi\left(d\left(x_{n-1}, x_{n}\right)\right) \\
& \cdots \\
\leq & \varphi^{n}\left(d\left(x_{0}, x_{1}\right)\right) .
\end{aligned}
$$

Hence

$$
\begin{aligned}
d\left(x_{n}, x_{n+m}\right) & \leq d\left(x_{n}, x_{n+1}\right)+d\left(x_{n+1}, x_{n+2}\right)+\cdots+d\left(x_{n+m-1}, x_{n+m}\right) \\
& \leq \varphi^{n}\left(d\left(x_{0}, x_{1}\right)\right)+\cdots+\varphi^{n+m-1}\left(d\left(x_{0}, x_{1}\right)\right) \\
& =\sum_{k=n}^{n+m-1} \varphi^{k}\left(d\left(x_{0}, x_{1}\right)\right) .
\end{aligned}
$$

Since $\sum_{n=1}^{\infty} \varphi^{n}\left(d\left(x_{0}, x_{1}\right)\right)<\infty$, then $\left\{x_{n}\right\}$ is a Cauchy sequence in $X$. Now, from the completeness of $X$, there exists $x \in X$ such that $x_{n} \rightarrow x$ as $n \rightarrow+\infty$ and since consecutive terms of $\left\{x_{n}\right\}$ are comparable, by hypothesis also $x_{n}$ and $x$ are comparable for all $n$. Now, we claim that $p_{\alpha}\left(x, T_{2} x\right)=0$ for each $\alpha \in[0,1]$. If not, then for some $\alpha \in[0,1]$, we have $p_{\alpha}\left(x, T_{2} x\right)>0$. Consider

$$
\begin{aligned}
p_{\alpha}\left(x, T_{2} x\right) \leq & d\left(x, x_{2 n+1}\right)+p_{\alpha}\left(x_{2 n+1}, T_{2} x\right) \\
\leq & d\left(x, x_{2 n+1}\right)+D_{\alpha}\left(T_{1} x_{2 n}, T_{2} x\right) \\
\leq & d\left(x, x_{2 n+1}\right)+\varphi\left(\operatorname { m a x } \left\{d\left(x_{2 n}, x\right), p_{\alpha}\left(x_{2 n}, T_{1} x_{2 n}\right), p_{\alpha}\left(x, T_{2} x\right),\right.\right. \\
& \left.\left.\frac{1}{2}\left[p_{\alpha}\left(x_{2 n}, T_{2} x\right)+p_{\alpha}\left(x, T_{1} x_{2 n}\right)\right]\right\}\right) \\
& +\mathbf{L} \min \left\{p_{\alpha}\left(x_{2 n}, T_{1} x_{2 n}\right), p_{\alpha}\left(x, T_{2} x\right), p_{\alpha}\left(x_{2 n}, T_{2} x\right), p_{\alpha}\left(x, T_{1} x_{2 n}\right)\right\} \\
= & d\left(x, x_{2 n+1}\right)+\varphi\left(\operatorname { m a x } \left\{d\left(x_{2 n}, x\right), d\left(x_{2 n}, x_{2 n+1}\right), p_{\alpha}\left(x, T_{2} x\right),\right.\right. \\
& \left.\left.\frac{1}{2}\left[p_{\alpha}\left(x_{2 n}, T_{2} x\right)+d\left(x, x_{2 n+1}\right)\right]\right\}\right) \\
& +\mathbf{L} \min \left\{d\left(x_{2 n}, x_{2 n+1}\right), p_{\alpha}\left(x, T_{2} x\right), p_{\alpha}\left(x_{2 n}, T_{2} x\right), p_{\alpha}\left(x, T_{1} x_{2 n}\right)\right\} .
\end{aligned}
$$


We note that $d\left(x_{2 n}, x\right) \rightarrow 0, d\left(x_{2 n}, x_{2 n+1}\right) \rightarrow 0$, and $p_{\alpha}\left(x_{2 n}, T_{2} x\right) \rightarrow p_{\alpha}\left(x, T_{2} x\right)$ as $n \rightarrow+\infty$. This implies that there exists $n_{0} \in \mathbb{N}$ such that

$$
\max \left\{d\left(x_{2 n}, x\right), d\left(x_{2 n}, x_{2 n+1}\right), \frac{1}{2}\left[p_{\alpha}\left(x_{2 n}, T_{2} x\right)+d\left(x, x_{2 n+1}\right)\right]\right\} \leq p_{\alpha}\left(x, T_{2} x\right)
$$

for all $n \geq n_{0}$. Consequently, we have

$$
p_{\alpha}\left(x, T_{2} x\right) \leq \varphi\left(p_{\alpha}\left(x, T_{2} x\right)\right)+\mathbf{L} \min \left\{d\left(x_{2 n}, x_{2 n+1}\right), p_{\alpha}\left(x, T_{2} x\right), p_{\alpha}\left(x_{2 n}, T_{2} x\right), p_{\alpha}\left(x, T_{1} x_{2 n}\right)\right\}
$$

for all $n \geq n_{0}$, which on taking the limit as $n \rightarrow+\infty$ gives

$$
p_{\alpha}\left(x, T_{2} x\right) \leq \varphi\left(p_{\alpha}\left(x, T_{2} x\right)\right)<p_{\alpha}\left(x, T_{2} x\right)
$$

a contradiction. Hence $p_{\alpha}\left(x, T_{2} x\right)=0$ and so $x_{\alpha} \subset T_{2} x$. Similarly we deduce that $x_{\alpha} \subset$ $T_{1} x$.

From Theorem 3.2, assuming $\varphi(t)=q t$ with $0<q<1$ and $\mathbf{L}=0$, we deduce the following result.

Corollary 3.3 Let $(X, d, \preceq)$ be a complete ordered metric space and $T_{1}, T_{2}: X \rightarrow W_{\alpha}(X)$ be two fuzzy mappings satisfying

$$
D_{\alpha}\left(T_{1} x, T_{2} y\right) \leq q \max \left\{d(x, y), p_{\alpha}\left(x, T_{1} x\right), p_{\alpha}\left(y, T_{2} y\right), \frac{1}{2}\left[p_{\alpha}\left(x, T_{2} y\right)+p_{\alpha}\left(y, T_{1} x\right)\right]\right\}
$$

for all comparable elements $x, y \in X$. Also suppose that

(i) if $y \in\left(T_{1} x_{0}\right)_{\alpha}$, then $y, x_{0} \in X$ are comparable,

(ii) if $x, y \in X$ are comparable, then every $u \in\left(T_{1} x\right)_{\alpha}$ and every $v \in\left(T_{2} y\right)_{\alpha}$ are comparable,

(iii) if a sequence $\left\{x_{n}\right\}$ in $X$ converges to $x \in X$ and its consecutive terms are comparable, then $x_{n}$ and $x$ are comparable for all $n$.

Then there exists a point $x \in X$ such that $x_{\alpha} \subset T_{1} x$ and $x_{\alpha} \subset T_{2} x$.

Now, we give an illustrative example, by adapting Example 6 in [46]; also we refer to the same paper for a better understanding of the situation.

Example 3.4 Let $X=[0,1]$ endowed with the usual order of real numbers and the Euclidean metric $d(x, y)=|x-y|$ for all $x, y \in X$. Clearly $(X, d)$ is a complete (ordered) metric space. Let $\alpha \in(0,1 / 2)$ and define $\varphi:[0,+\infty) \rightarrow[0,+\infty)$ and $T_{1}, T_{2}: X \rightarrow W_{\alpha}(X)$ by

$$
\begin{aligned}
& \varphi(t)= \begin{cases}t^{3} /(1+t) & \text { if } x \in[0,1], \\
\frac{1}{2} & \text { if } x \in(1,+\infty),\end{cases} \\
& \left(T_{1} 0\right)(x)=\left(T_{2} 1\right)(x)= \begin{cases}1 & \text { if } x=0, \\
\alpha & \text { if } x \in(0,1 / 2] \\
\alpha / 2 & \text { if } x \in(1 / 2,1],\end{cases}
\end{aligned}
$$




$$
\begin{aligned}
& \left(T_{1} 1\right)(x)=\left(T_{2} 0\right)(x)= \begin{cases}1 & \text { if } x=0, \\
2 \alpha & \text { if } x \in(0,1 / 2], \\
\alpha / 2 & \text { if } x \in(1 / 2,1],\end{cases} \\
& \left(T_{1} z\right)(x)=\left(T_{2} z\right)(x)=\left\{\begin{array}{ll}
1 & \text { if } x=0, \\
\alpha & \text { if } x \in(0,1 / 2], \\
0 & \text { if } x \in(1 / 2,1],
\end{array} \text { where } z \in(0,1) .\right.
\end{aligned}
$$

Then we discuss the existence of fixed fuzzy points of mappings $T_{1}$ and $T_{2}$. To this aim, we note that $\left(T_{i} 0\right)_{\alpha}=\left(T_{i} z\right)_{\alpha}=\left(T_{i} 1\right)_{\alpha}=[0,1 / 2],\left(T_{i} 0\right)_{\alpha / 2}=\left(T_{i} 1\right)_{\alpha / 2}=[0,1]$, and $\left(T_{i} z\right)_{\alpha / 2}=$ $[0,1 / 2]$, where $i=1,2$. Consequently, it is easy to show (see also [46]) that all the hypotheses of Theorem 3.2 are satisfied. In particular, condition (1) holds trivially since $D_{\alpha}\left(T_{1} x, T_{2} y\right)=0$ for all $x, y \in X$. We conclude that each $x \in[0,1 / 2]$ is such that $x_{\alpha} \subset T_{1} x$ and $x_{\alpha} \subset T_{2} x$.

On the other hand, in view of Definition 2.4, we can apply our Theorem 3.2 to establish the existence of a common fixed point of $T_{1}$ and $T_{2}$. In this case, we note that $\left(T_{i} 0\right)_{1}=$ $\left(T_{i} z\right)_{1}=\left(T_{i} 1\right)_{1}=\{0\}$, and hence $x=0$ is a common fixed point of $T_{1}$ and $T_{2}$.

Now, we briefly discuss the validity of our theorem. In fact, a question that arises naturally is: 'Is it possible to prove this kind of result without assuming that $\sum_{n=1}^{\infty} \varphi^{n}(t)<\infty$ for all $t>0$ ?'. In the sequel we provide a positive answer to the above question. Precisely, Theorem 3.2 still holds if the condition:

(a) $\varphi:[0,+\infty) \rightarrow[0,+\infty)$ is a nondecreasing function such that $\sum_{n=1}^{\infty} \varphi^{n}(t)<\infty$ for all $t>0$,

is replaced by

(b) $\varphi:[0,+\infty) \rightarrow[0,+\infty)$ is a right-continuous function such that $\varphi(t)<t$ for all $t>0$.

Next, we give the proof of Theorem 3.2 under condition (b). To this aim, we recall the following lemma.

Lemma 3.5 Let $(X, d)$ be a metric space and let $\left\{x_{n}\right\}$ be a sequence in $X$ such that

$$
\lim _{n \rightarrow+\infty} d\left(x_{n}, x_{n+1}\right)=0 .
$$

If $\left\{x_{2 n}\right\}$ is not a Cauchy sequence, then there exist $\varepsilon>0$ and two sequences $\left\{m_{k}\right\}$ and $\left\{n_{k}\right\}$ of positive integers such that the following four sequences converge to $\varepsilon$ when $k \rightarrow+\infty$ :

$$
\begin{aligned}
& \left\{d\left(x_{2 m_{k}}, x_{2 n_{k}}\right)\right\}, \quad\left\{d\left(x_{2 m_{k}}, x_{2 n_{k}+1}\right)\right\}, \\
& \left\{d\left(x_{2 m_{k}-1}, x_{2 n_{k}}\right)\right\}, \quad\left\{d\left(x_{2 m_{k}-1}, x_{2 n_{k}+1}\right)\right\} .
\end{aligned}
$$

Remark 3.6 Note that assertions similar to the above lemma (see, for example, [10]) were proved and used to obtain several fixed point results in many papers.

Finally, we state and prove the following result.

Theorem 3.7 Let $(X, d, \preceq)$ be a complete ordered metric space and $T_{1}, T_{2}: X \rightarrow W_{\alpha}(X)$ be two fuzzy mappings satisfying

$$
D_{\alpha}\left(T_{1} x, T_{2} y\right) \leq \varphi(M(x, y))+\mathbf{L} \min \left\{p_{\alpha}\left(x, T_{1} x\right), p_{\alpha}\left(y, T_{2} y\right), p_{\alpha}\left(x, T_{2} y\right), p_{\alpha}\left(y, T_{1} x\right)\right\}
$$


for all comparable elements $x, y \in X$, where $\mathbf{L} \geq 0$,

$$
M(x, y)=\max \left\{d(x, y), p_{\alpha}\left(x, T_{1} x\right), p_{\alpha}\left(y, T_{2} y\right), \frac{1}{2}\left[p_{\alpha}\left(x, T_{2} y\right)+p_{\alpha}\left(y, T_{1} x\right)\right]\right\}
$$

and $\varphi:[0,+\infty) \rightarrow[0,+\infty)$ is a right-continuous function such that $\varphi(t)<t$ for all $t>0$. Suppose that

(i) if $y \in\left(T_{1} x_{0}\right)_{\alpha}$, then $y, x_{0} \in X$ are comparable,

(ii) if $x, y \in X$ are comparable, then every $u \in\left(T_{1} x\right)_{\alpha}$ and every $v \in\left(T_{2} y\right)_{\alpha}$ are comparable,

(iii) if a sequence $\left\{x_{n}\right\}$ in $X$ converges to $x \in X$ and its consecutive terms are comparable, then $x_{n}$ and $x$ are comparable for all $n$.

Then there exists a point $x \in X$ such that $x_{\alpha} \subset T_{1} x$ and $x_{\alpha} \subset T_{2} x$.

Proof Following the proof of Theorem 3.2, we can construct a sequence $\left\{x_{n}\right\}$ such that (3) and (4) hold. It follows that

$$
d\left(x_{n}, x_{n+1}\right)<d\left(x_{n-1}, x_{n}\right) \quad \text { for all } n .
$$

Thus, in this case $\left\{d\left(x_{n}, x_{n+1}\right)\right\}$ is a decreasing sequence of positive numbers and so there exists $r \geq 0$ such that $\lim _{n \rightarrow+\infty} d\left(x_{n}, x_{n+1}\right)=r$. Now, if $r>0$, then passing to the limit when $n \rightarrow+\infty$ in $d\left(x_{n}, x_{n+1}\right) \leq \varphi\left(d\left(x_{n-1}, x_{n}\right)\right)$, and using the properties of $\varphi$, we get

$$
r \leq \varphi(r)<r
$$

a contradiction and so we have proved that $\lim _{n \rightarrow+\infty} d\left(x_{n}, x_{n+1}\right)=r=0$.

Now, suppose that $\left\{x_{2 n}\right\}$ is not a Cauchy sequence. Then Lemma 3.5 implies that there exist $\varepsilon>0$ and two sequences $\left\{m_{k}\right\}$ and $\left\{n_{k}\right\}$ of positive integers such that the sequences (6) converge to $\varepsilon$ (from above) when $k \rightarrow+\infty$. Therefore, using (7) with $x=x_{2 m_{k}}$ and $y=x_{2 n_{k}+1}$, we get

$$
\begin{aligned}
D_{\alpha}\left(T_{1} x_{2 m_{k}}, T_{2} x_{2 n_{k}+1}\right) \leq & \varphi\left(M\left(x_{2 m_{k}}, x_{2 n_{k}+1}\right)\right)+\mathbf{L} \min \left\{p_{\alpha}\left(x_{2 m_{k}}, T_{1} x_{2 m_{k}}\right),\right. \\
& p_{\alpha}\left(x_{2 n_{k}+1}, T_{2} x_{2 n_{k}+1}\right), p_{\alpha}\left(x_{2 m_{k}}, T_{2} x_{2 n_{k}+1}\right), \\
& \left.p_{\alpha}\left(x_{2 n_{k}+1}, T_{1} x_{2 m_{k}}\right)\right\}
\end{aligned}
$$

where

$$
\begin{aligned}
M\left(x_{2 m_{k}}, x_{2 n_{k}+1}\right)= & \max \left\{d\left(x_{2 m_{k}}, x_{2 n_{k}+1}\right), p_{\alpha}\left(x_{2 m_{k}}, T_{1} x_{2 m_{k}}\right), p_{\alpha}\left(x_{2 n_{k}+1}, T_{2} x_{2 n_{k}+1}\right),\right. \\
& \left.\frac{1}{2}\left[p_{\alpha}\left(x_{2 m_{k}}, T_{2} x_{2 n_{k}+1}\right)+p_{\alpha}\left(x_{2 n_{k}+1}, T_{1} x_{2 m_{k}}\right)\right]\right\} \\
\rightarrow & \varepsilon, \quad \text { as } k \rightarrow+\infty .
\end{aligned}
$$

Using the properties of $\varphi$, we obtain the contradiction $\varepsilon \leq \varphi(\varepsilon)<\varepsilon$, since $\varepsilon>0$. Thus $\left\{x_{2 n}\right\}$ is a Cauchy sequence and hence also $\left\{x_{n}\right\}$ is a Cauchy sequence. The rest of the proof is the same as the proof of Theorem 3.2 and so to avoid repetition we omit the details. 
To conclude this section, we give an example to illustrate Theorem 3.7, in the case of a single mapping.

Example 3.8 Let $a, b$, and $c$ be three real numbers such that $a<b<c$ and consider $X=$ $\{a, b, c\}$ endowed with the Euclidean metric $d(x, y)=|x-y|$ for all $x, y \in X$. Let $\alpha \in(0,1 / 3)$ and define $\varphi:[0,+\infty) \rightarrow[0,+\infty)$ by

$$
\varphi(t)= \begin{cases}t^{2} / 2 & \text { if } t \leq 1 \\ \sqrt{t} / 2 & \text { if } t>1\end{cases}
$$

and $T: X \rightarrow W_{\alpha}(X)$ by

$$
(T a)(x)=(T b)(x)=\left\{\begin{array}{ll}
1 & \text { if } x=a, \\
\alpha / 2 & \text { if } x=b, \\
\alpha & \text { if } x=c,
\end{array} \quad(T c)(x)= \begin{cases}1 & \text { if } x=a, \\
\alpha / 2 & \text { if } x=b, \\
3 \alpha & \text { if } x=c .\end{cases}\right.
$$

Firstly, searching for fixed fuzzy points, we notice that $(T a)_{\alpha / 2}=(T b)_{\alpha / 2}=(T c)_{\alpha / 2}=\{a, b, c\}$ and $(T a)_{\alpha}=(T b)_{\alpha}=(T c)_{\alpha}=\{a, c\}$. Also, it is easy to show that all the hypotheses of Theorem 3.7 with $T_{1}=T_{2}=T$ are satisfied and hence $c_{\alpha}$ is a fixed fuzzy point of $X$. Secondly, searching for fixed points, from $(T a)_{1}=(T b)_{1}=(T c)_{1}=\{a\}$ we deduce that $a$ is a fixed point of $T$.

\section{Application to ordinary fuzzy differential equation}

In this section, we present a situation where our obtained results can be applied. Precisely, we study the existence of solution for the second order nonlinear boundary value problem:

$$
\begin{cases}x^{\prime \prime}(t)=k\left(t, x(t), x^{\prime}(t)\right), & t \in[0, \Lambda], \Lambda>0, \\ x\left(t_{1}\right)=x_{1}, & t_{1}, t_{2} \in[0, \Lambda], \\ x\left(t_{2}\right)=x_{2}, & \end{cases}
$$

where $k:[0, \Lambda] \times W(X) \times W(X) \rightarrow W(X)$ is a continuous function. This problem is equivalent to the integral equation

$$
x(t)=\int_{t_{1}}^{t_{2}} G(t, s) k\left(s, x(s), x^{\prime}(s)\right) d s+\beta(t), \quad t \in[0, \Lambda],
$$

where the Green's function $G$ is given by

$$
G(t, s)= \begin{cases}\frac{\left(t_{2}-t\right)\left(s-t_{1}\right)}{t_{2}-t_{1}} & \text { if } t_{1} \leq s \leq t \leq t_{2} \\ \frac{\left(t_{2}-s\right)\left(t-t_{1}\right)}{t_{2}-t_{1}} & \text { if } t_{1} \leq t \leq s \leq t_{2}\end{cases}
$$

and $\beta(t)$ satisfies $\beta^{\prime \prime}=0, \beta\left(t_{1}\right)=x_{1}, \beta\left(t_{2}\right)=x_{2}$. Let us recall some properties of $G(t, s)$, precisely we have

$$
\int_{t_{1}}^{t_{2}}|G(t, s)| d s \leq \frac{\left(t_{2}-t_{1}\right)^{2}}{8}
$$


and

$$
\int_{t_{1}}^{t_{2}}\left|G_{t}(t, s)\right| d s \leq \frac{\left(t_{2}-t_{1}\right)}{2}
$$

If necessary, the reader can refer to $[47,48]$ for a more detailed explanation of the background of the problem. Here, we shall prove our result, by establishing the existence of a common fixed point for a pair of integral operators defined as

$$
T_{i}(x)(t)=\int_{t_{1}}^{t_{2}} G(t, s) k_{i}\left(s, x(s), x^{\prime}(s)\right) d s+\beta(t), \quad t \in[0, \Lambda], i \in\{1,2\}
$$

where $k_{1}, k_{2} \in C([0, \Lambda] \times W(X) \times W(X), W(X)), x \in C^{1}([0, \Lambda], W(X))$, and $\beta \in C([0, \Lambda]$, $W(X))$.

Theorem 4.1 Assume that the following conditions are satisfied:

(a) $k_{1}, k_{2}:[0, \Lambda] \times W(X) \times W(X) \rightarrow W(X)$ are increasing in its second and third variables

(b) there exists $x_{0} \in C^{1}([0, \Lambda], W(X))$ such that, for all $t \in[0, \Lambda]$, we have

$$
x_{0}(t) \leq \int_{t_{1}}^{t_{2}} G(t, s) k_{1}\left(t, x_{0}(s), x_{0}^{\prime}(s)\right) d s+\beta(t) \text {, }
$$

where $t_{1}, t_{2} \in[0, \Lambda]$,

(c) there exist $\gamma, \delta>0$ such that, for all $t \in[0, \Lambda]$, we have

$$
\left|k_{1}\left(t, x(t), x^{\prime}(t)\right)-k_{2}\left(t, y(t), y^{\prime}(t)\right)\right| \leq \gamma|x(t)-y(t)|+\delta\left|x^{\prime}(t)-y^{\prime}(t)\right|
$$

for all comparable $x, y \in C^{1}([0, \Lambda], W(X))$,

(d) for $\gamma, \delta>0$ and $t_{1}, t_{2} \in[0, \Lambda]$ we have

$$
\gamma \frac{\left(t_{2}-t_{1}\right)^{2}}{8}+\delta \frac{\left(t_{2}-t_{1}\right)}{2}<1
$$

(e) if $x, y \in C^{1}([0, \Lambda], W(X))$ are comparable, then every $u \in\left(T_{1} x\right)_{1}$ and every $v \in\left(T_{2} y\right)_{1}$ are comparable.

Then the pair of nonlinear integral equations

$$
x(t)=\int_{t_{1}}^{t_{2}} G(t, s) k_{i}\left(s, x(s), x^{\prime}(s)\right) d s+\beta(t), \quad t \in[0, \Lambda], i \in\{1,2\}
$$

has a common solution in $C^{1}\left(\left[t_{1}, t_{2}\right], W(X)\right)$.

Proof Consider $\mathcal{C}=C^{1}\left(\left[t_{1}, t_{2}\right], W(X)\right)$ with the metric

$$
D(x, y)=\max _{t_{1} \leq t \leq t_{2}}\left(\gamma|x(t)-y(t)|+\delta\left|x^{\prime}(t)-y^{\prime}(t)\right|\right) .
$$

The space $(\mathcal{C}, D)$ is a complete metric space, which can also be equipped with the partial ordering given by

$$
x, y \in \mathcal{C}, \quad x \preceq y \quad \Leftrightarrow x(t) \quad \leq y(t) \quad \text { for all } t \in[0, \Lambda] .
$$


In [12], it is proved that $(\mathcal{C}, \preceq)$ satisfies the following condition:

(r) for every nondecreasing sequence $\left\{x_{n}\right\}$ in $\mathcal{C}$ convergent to some $x \in \mathcal{C}$, we have $x_{n} \preceq x$ for all $n \in \mathbb{N} \cup\{0\}$.

Let $T_{1}, T_{2}: \mathcal{C} \rightarrow \mathcal{C}$ be two integral operators defined by (12); clearly, $T_{1}, T_{2}$ are well defined since $k_{1}, k_{2}$, and $\beta$ are continuous functions. Now, $x^{*}$ is a solution of (13) if and only if $x^{*}$ is a common fixed point of $T_{1}$ and $T_{2}$.

By hypothesis (a), $T_{1}, T_{2}$ are increasing and, by hypothesis (b), $x_{0} \preceq T_{1}\left(x_{0}\right)$. Consequently, in view of condition (r), hypotheses (i)-(iii) of Corollary 3.3 hold true.

Next, for all comparable $x, y \in \mathcal{C}$, by hypothesis (c) we have successively

$$
\begin{aligned}
\left|T_{1}(x)(t)-T_{2}(y)(t)\right| & \leq \int_{t_{1}}^{t_{2}}|G(t, s)|\left|k_{1}\left(s, x(s), x^{\prime}(s)\right)-k_{2}\left(s, y(s), y^{\prime}(s)\right)\right| d s \\
& \leq D(x, y) \int_{t_{1}}^{t_{2}}|G(t, s)| d s \leq \frac{\left(t_{2}-t_{1}\right)^{2}}{8} D(x, y)
\end{aligned}
$$

and

$$
\begin{aligned}
\left|\left(T_{1}(x)\right)^{\prime}(t)-\left(T_{2}(y)\right)^{\prime}(t)\right| & \leq \int_{t_{1}}^{t_{2}}\left|G_{t}(t, s)\right|\left|k_{1}\left(s, x(s), x^{\prime}(s)\right)-k_{2}\left(s, y(s), y^{\prime}(s)\right)\right| d s \\
& \leq D(x, y) \int_{t_{1}}^{t_{2}}\left|G_{t}(t, s)\right| d s \leq \frac{\left(t_{2}-t_{1}\right)}{2} D(x, y) .
\end{aligned}
$$

From (14) and (15), we obtain easily

$$
D\left(T_{1} x, T_{2} y\right) \leq\left(\gamma \frac{\left(t_{2}-t_{1}\right)^{2}}{8}+\delta \frac{\left(t_{2}-t_{1}\right)}{2}\right) D(x, y) .
$$

Consequently, in view of hypothesis (d), the contractive condition (5) is satisfied with

$$
q=\gamma \frac{\left(t_{2}-t_{1}\right)^{2}}{8}+\delta \frac{\left(t_{2}-t_{1}\right)}{2}<1 .
$$

Therefore, Corollary 3.3 applies to $T_{1}$ and $T_{2}$, which have a common fixed point $x^{*} \in \mathcal{C}$, that is, $x^{*}$ is a common solution of (13).

As an immediate consequence of Theorem 4.1, in the case $T_{1}=T_{2}=T$, we find that the integral equation (11) has a solution in $\mathcal{C}$, and hence the second order nonlinear boundary value problem (10) has a solution.

\section{Conclusions}

Our Theorem 3.2 gives a contribution to the 'fixed point arena' in the sense of generalization by using fuzziness under ordered metric spaces and by assuming the validity of the contractive condition only on elements that are comparable in respect to partial ordering. Moreover, using recent ideas in the literature [13,23, 24, 31], it is possible to extend our result to non-Archimedean fuzzy metric spaces and probabilistic metric spaces endowed with a partial ordering induced by an appropriate function. 
Authors' contributions

All authors contributed equally and significantly in writing this paper. All authors read and approved the final manuscript.

\section{Author details}

'Department of Mathematics, Disha Institute of Management and Technology, Satya Vihar, Vidhansabha-Chandrakhuri Marg, Mandir Hasaud, Raipur, Chhattisgarh 492101, India. ²Dipartimento di Matematica e Informatica, Università degli Studi di Palermo, via Archirafi 34, Palermo, 90123, Italy. ${ }^{3}$ Department of Mathematics and Computer Science, Faculty of Science and Technology, Rajamangala University of Technology Thanyaburi (RMUTT), 39, Moo 1, Rangsit-Nakhonnayok Rd., Klong 6, Thanyaburi, Pathumthani, 12110, Thailand. ${ }^{4}$ Department of Mathematics, Faculty of Science, King Mongkut's University of Technology Thonburi (KMUTT), Bangkok, 10140, Thailand.

\section{Authors' information}

C Vetro is member of the Gruppo Nazionale per l'Analisi Matematica, la Probabilità e le loro Applicazioni (GNAMPA) of the Istituto Nazionale di Alta Matematica (INdAM)

\section{Acknowledgements}

The authors thank the referees for their valuable comments and suggestions for the improvement of the manuscript. Moreover, W Kumam was supported by the National Research Council of Thailand (NRCT 2013-2014) and P Kumam was supported by the Higher Education Research Promotion and National Research University Project of Thailand, Office of the Higher Education Commission (Under NUR Project 'Theoretical and Computational fixed points for Optimization problems' No. 57000621).

\section{Received: 28 April 2014 Accepted: 25 July 2014 Published: 20 Aug 2014}

\section{References}

1. Banach, S: Sur les opérations dans les ensembles abstraits et leur application aux équations intégrales. Fundam. Math. 3, 133-181 (1922)

2. Tasković, MR: Some new principles in fixed point theory. Math. Jpn. 4, 645-666 (1990)

3. Khan, MS, Swaleh, M, Sessa, S: Fixed point theorems by altering distances between the points. Bull. Aust. Math. Soc. 30, 1-9 (1984)

4. Abbas, M, Ali Khan, M: Common fixed point theorem of two mappings satisfying a generalized weak contractive condition. Int. J. Math. Math. Sci. 2009, Article ID 131068 (2009)

5. Dutta, PN, Choudhury, BS: A generalization of contraction principle in metric spaces. Fixed Point Theory Appl. 2008, Article ID 406368 (2008)

6. Rhoades, BE: Some theorems on weakly contractive maps. Nonlinear Anal. 47, 2683-2693 (2001)

7. Alber, YI, Guerre-Delabriere, S: Principles of weakly contractive maps in Hilbert spaces. In: Gohberg, I, Lyubich, Y (eds.) New Results in Operator Theory and Its Applications. Oper. Theory Adv. Appl., vol. 98, pp. 7-22. Birkhäuser, Basel (1997)

8. Azam, A, Arshad, M, Vetro, P: On a pair of fuzzy $\varphi$-contractive mappings. Math. Comput. Model. 52, $207-214$ (2010)

9. Nashine, HK: New fixed point theorems for mappings satisfying generalized weakly contractive condition with weaker control functions. Ann. Pol. Math. 104, 109-119 (2011)

10. Radenović, S, Kadelburg, Z, Jandrlić, D, Jandrlić, A: Some results on weak contraction maps. Bull. Iran. Math. Soc. 38, 625-645 (2012)

11. Ran, ACM, Reurings, MCB: A fixed point theorem in partially ordered sets and some applications to matrix equations. Proc. Am. Math. Soc. 132(5), 1435-1443 (2004)

12. Nieto, JJ, Rodríguez-López, R: Contractive mapping theorems in partially ordered sets and applications to ordinary differential equations. Order 22(3), 223-239 (2005)

13. Ćirić, LB, Mihet, D, Saadati, R: Monotone generalized contractions in partially ordered probabilistic metric spaces. Topol. Appl. 156, 2838-2844 (2009)

14. Abbas, M, Sintunavarat, W, Kumam, P: Coupled fixed point of generalized contractive mappings on partially ordered G-metric spaces. Fixed Point Theory Appl. 2012, 31 (2012)

15. Saadati, R, Vaezpour, SM, Vetro, P, Rhoades, BE: Fixed point theorems in generalized partially ordered G-metric spaces. Math. Comput. Model. 52, 797-801 (2010)

16. Shatanawi, W: Partially ordered cone metric spaces and coupled fixed point results. Comput. Math. Appl. 60, 2508-2515 (2010)

17. Ćirić, LB, Abbas, M, Damjanović, B, Saadati, R: Common fuzzy fixed point theorems in ordered metric spaces. Math. Comput. Model. 53, 1737-1741 (2011)

18. Shakeri, S, Ćirić, LB, Saadati, R: Common fixed point theorem in partially ordered $\mathcal{L}$-fuzzy metric spaces. Fixed Point Theory Appl. 2010, Article ID 125082 (2010)

19. Sintunavarat, W, Kumam, P: Common fixed point theorems for a pair of weakly compatible mappings in fuzzy metric spaces. J. Appl. Math. 2011, Article ID 637958 (2011)

20. Sintunavarat, W, Kumam, P: Fixed point theorems for a generalized intuitionistic fuzzy contraction in intuitionistic fuzzy metric spaces. Thai J. Math. 10(1), 123-135 (2012)

21. Sintunavarat, $W$, Kumam, $P$ : Common fixed points for $R$-weakly commuting in fuzzy metric spaces. Ann. Univ. Ferrara 58(2), 389-406 (2012)

22. Chauhan, S, Bhatnagar, S, Radenović, S: Common fixed point theorems for weakly compatible mappings in fuzzy metric spaces. Matematiche LXVIII(I), 87-98 (2013). doi:10.4418/2013.68.1.8

23. Altun, I: Some fixed point theorems for single and multi valued mappings on ordered non-Archimedean fuzzy metric spaces. Iran. J. Fuzzy Syst. 7(1), 91-96 (2010)

24. Altun, I, Mihet, D: Ordered non-Archimedean fuzzy metric spaces and some fixed point results. Fixed Point Theory Appl. 2010, Article ID 782680 (2010)

25. Nashine, HK, Altun, I: Fixed point theorems for generalized weakly contractive condition in ordered metric spaces. Fixed Point Theory Appl. 2011, Article ID 132367 (2011) 
26. Nashine, HK, Altun, I: A common fixed point theorem on ordered metric spaces. Bull. Iran. Math. Soc. 38(4), 925-934 (2012)

27. Nashine, HK, Samet, B: Fixed point results for mappings satisfying $(\psi, \varphi)$-weakly contractive condition in partially ordered metric spaces. Nonlinear Anal. 74, 2201-2209 (2011)

28. Nashine, HK, Samet, B, Vetro, C: Monotone generalized nonlinear contractions and fixed point theorems in ordered metric spaces. Math. Comput. Model. 54, 712-720 (2011)

29. O'Regan, D, Petrusel, A: Fixed point theorems for generalized contractions in ordered metric spaces. J. Math. Anal. Appl. 341, 1241-1252 (2008)

30. Sintunavarat, W, Cho, YJ, Kumam, P: Coupled coincidence point theorems for contractions without commutative condition in intuitionistic fuzzy normed spaces. Fixed Point Theory Appl. 2011, 81 (2011)

31. Chauhan, S, Imdad, M, Radenović, S, Vetro, C: Some integral type fixed point theorems in non-Archimedean Menger PM-spaces with common property (E.A) and application of functional equations in dynamic programming. Rev. R. Acad. Cienc. Exactas Fís. Nat., Ser. A Mat. (2013). doi:10.1007/s13398-013-0142-6

32. Zadeh, LA: Fuzzy sets. Inf. Control 8, 103-112 (1965)

33. Heilpern, S: Fuzzy mappings and fixed point theorems. J. Math. Anal. Appl. 83, 566-569 (1981)

34. Estruch, VD, Vidal, A: A note on fixed fuzzy points for fuzzy mappings. Rend. Ist. Mat. Univ. Trieste 32, $39-45$ (2001)

35. Abbas, M, Damjanović, B, Lazović, R: Fuzzy common fixed point theorems for generalized contractive mappings. Appl. Math. Lett. 23(11), 1326-1330 (2010)

36. Onjai-uea, N, Kumam, P: A generalized nonlinear random equations with random fuzzy mappings in uniformly smooth Banach spaces. J. Inequal. Appl. 2010, Article ID 728452 (2010)

37. Rashwan, RA, Ahmed, MA: Common fixed point theorems for fuzzy mappings. Arch. Math. 38, 219-226 (2002)

38. Chaipunya, P, Cho, YJ, Kumam, P: Geraghty-type theorems in modular metric spaces with an application to partial differential equation. Adv. Differ. Equ. 2012, 83 (2012)

39. Nashine, HK, Kadelburg, Z, Kumam, P: Implicit relation type cyclic contractive mappings and applications to integral equations. Abstr. Appl. Anal. 2012, Article ID 386253 (2012)

40. Nashine, HK, Sintunavarat, W, Kumam, P: Cyclic generalized contractions and fixed point results with applications to an integral equation. Fixed Point Theory Appl. 2012, 217 (2012). doi:10.1186/1687-1812-2012-217

41. Sintunavarat, W, Cho, YJ, Kumam, P: Urysohn integral equations approach by common fixed points in complex valued metric spaces. Adv. Differ. Equ. 2013, 49 (2013). doi:10.1186/1687-1847-2013-49

42. Sintunavarat, W, Kumam, P: Coupled fixed point results for nonlinear integral equations. J. Egypt. Math. Soc. 21 266-272 (2013)

43. Nashine, HK, Pathak, RP, Somvanshi, PS, Pantelic, S, Kumam, P: Solutions for a class of nonlinear Volterra integral and integro-differential equation using cyclic $(\varphi, \psi, \theta)$-contraction. Adv. Differ. Equ. 2013, 106 (2013). doi:10.1186/1687-1847-2013-106

44. Pathak, HK, Hussain, N: Common fixed points for Banach pairs with applications. Nonlinear Anal. 69, 2788-2802 (2008)

45. Pu, P-M, Liu, Y-M: Fuzzy topology. I. Neighborhood structure of a fuzzy point and Moore-Smith convergence. J. Math. Anal. Appl. 76, 571-599 (1980)

46. Turkoglu, D, Rhoades, BE: A fixed fuzzy point for fuzzy mapping in complete metric spaces. Math. Commun. 10 115-121 (2005)

47. Lakshmikantham, V, Mohapatra, R: Theory of Fuzzy Differential Equations and Inclusions. Taylor \& Francis, London (2003)

48. Puri, M, Ralescu, D: Fuzzy random variables. J. Math. Anal. Appl. 114, 409-422 (1986)

10.1186/1687-1847-2014-232

Cite this article as: Nashine et al.: Fixed point theorems for fuzzy mappings and applications to ordinary fuzzy

differential equations. Advances in Difference Equations 2014, 2014:232

\section{Submit your manuscript to a SpringerOpen ${ }^{\circledR}$ journal and benefit from:}

- Convenient online submission

Rigorous peer review

- Immediate publication on acceptance

- Open access: articles freely available online

- High visibility within the field

- Retaining the copyright to your article

Submit your next manuscript at $>$ springeropen.com 